\title{
DATA WAREHOUSE DESIGN WITH KIMBALL METHOD: CASE STUDY OF FARHRENHEIT MANUFACTURING SYSTEMS
}

\author{
Widianty \\ Information Systems Department, School of Information Systems, BINUS University \\ Jl.K.H.Syahdan no 9, Palmerah, Jakarta Barat 11480 \\ widianty@gmail.com
}

\begin{abstract}
Competition in the business world that increasingly stringent requires management to make decisions accurately and quickly. It is also felt by Farhenheit as entrepreneurs. To achieve thier forte in competing in the global competition, he needs systems like strategic decision makers which is up-to-date reliable and fast. Then the solution of area manufatur datawarehouse design is necessary to support the above objectives,i.e. : the right and fast decisions. However, Fahrenheit only has ERP as their core system currently and they do not have management support system. They have some difficulty to understand some problems and do better analysis. There are some datawarehouse development methodologies. Methods that will be used for the development of datawarehouse design is Kimball Method. Kimball method was chosen because of its development process that follows the business process is very suitable for the development of datawarehouse gradually to a company. Kimball's method gives a mart for the related business processes. This study is conducted by interview and survey from several senior managers and directors in Fahrenheit to know about their requirement and how they do analyzesis currently
\end{abstract}

Keywords: Kimball method, datawarehouse design

\begin{abstract}
ABSTRAK
Persaingan di dalam dunia bisnis yang semakin ketat membutuhkan managemen untuk mengambil keputusan secara tepat dan cepat. Hal tersebut juga dirasakan oleh Farhenheit sebagai pelaku usaha. Untuk meraih keungulan bersaingannya dalam persaingan global maka mereka membutuhkan sistem pengambil keputusan strategis yang up-to-date, terpercaya dan cepat. Oleh karena itu, solusi perancangan datawarehouse untuk area manufacture dirasakan perlu untuk menunjang tujuan diatas, yaitu :mengambil keputusan secara tepat dan cepat. Namun, saat ini Fahrenheit hanya mengunakan ERP sebagai sistem utamanya dan belum ada sistem penunjang pengambilan keputusan. Terdapat beberapa metodologi pengembangan datawarehouse. Metode yang akan diambil untuk pengembangan rancangan datawarehouse ini adalah Metode Kimball. Metode Kimball ini dipilih karena proses pengembangannya yang mengikuti proses bisnis sangat cocok untuk pengembangan datawarehouse secara bertahap untuk suatu perusahaan. Metode Kimball ini memberikan satu mart untuk satu proses bisnis terkait. Penulisan ini dilakukan dengan melakukan wawancara dan survei ke beberapa senior manager dan direksi di Fahrenheit untuk mengetahui tentang kebutuhan mereka dan bagaimana mereka melakukan analisis saat ini.
\end{abstract}

Kata kunci: Metode Kimball, rancangan datawarehouse 


\section{PENDAHULUAN}

Saat ini persaingan di dalam dunia bisnis semakin ketat, sehingga membutuhkan pengambilan keputusan manajemen yang tepat dan cepat. Untuk meraih keunggulan dalam persaingan global maka perusahaan membutuhkan sistem pengambil keputusan strategis yang up-to-date, terpercaya dan cepat. Berdasarkan hal tersebut, solusi untuk membangun dan merancang datawarehouse sangat diperlukan.

Saat ini perusahaan Fahrenheit sudah melakukan implementasi ERP dan sudah dijalankan selama tiga tahun. Namum pemanfaatan terhadap keputusan manajemen belum besar. Laporan yang dihasilkan oleh ERP masih bersifat operasional sehingga butuh resource dan waktu untuk mengolah menjadi informasi yang bersifat strategis dan bisa dipakai dalam proses pengambilan keputusan. Sebuah perusahaan perlu mengembangkan datawarehouse sebagai basis data untuk menghasilkan informasi yang bersifat strategis dalam menunjang proses pengambilan keputusan yang lebih cepat dan baik. Saxena (2014) mengatakan, "Datawarehouse adalah seperti gudang data yang dapat dipresentasikan dalam berbagai bentuk."

Datawarehouse merupakan dasar untuk membuat sistem penunjang pengambilan keputusan yang sering disebut Business Intelligent atau BI. Marketa (2013) mengatakan, "Contoh keluaran dari BI adalah informasi dari ketidakefektifan atau ketidakefisiensian dari suatu produk, aktifitas pelayanan suatu perusahaan dan proses, pengembangan dari informasi ini dalam waktu dan informasi yang lebih lanjut, dapat membantu mengelola perusahaan agar lebih sukses.

Tujuan penelitian ini adalah untuk menghasilkan perancangan Datawarehouse dengan metode Kimball dengan studi kasus sistem manufatur Fahrenheit. Manfaat dari penelitian ini adalah: (1) Menyediakan rancangan datawarehouse dengan metode Kimball untuk mendukung penerapan sistem penunjang pengambilan keputusan untuk managemen. (2) Memberikan bukti-bukti terkait pengunaan sistem penunjang pengambilan keputusan merupakan hal yang sangat diperlukan oleh perusahaan untuk dapat bersaing dalam kondisi pasar saat ini. Ruang lingkup rancangan datawarehouse pada tulisan ini hanya menghasilkan dimensional modeling pada area analisa manufakturing saja. Hasil interview kebutuhan bisnis sengaja penulis tidak tampilkan untuk menjaga kerahasiaan data.

\section{METODE}

Dalam melakukan perancangan Datawarehouse di Fahrenheit, digunakan beberapa metode yang akan dilakukan. Pertama, Metode Analisis: pada proses analisis ini, studi kepustakaan akan dilakukan pada literatur yang berkaitan dengan pengembangan Datawarehouse Life Cycle. Selain itu, wawancara terhadap top management mengenai kebutuhan-kebutuhan analisa mereka akan dilakukan. Berdasarkan dua hal di atas dan juga pengalaman peneliti sebagai praktisi di bidang pengembangan datawarehouse dan business intelligent, maka analisa dapat dilakuakan dengan lebih rinci. Metode pengumpulan data berupa survei dari beberapa senior manager dan direksi dari Fahrenheit di beberapa divisi. Kemudian, beberapa contoh laporan yang dipakai oleh para manager dan direksi dikumpulkan dengan periode harian, mingguan dan bulanan dan data-data tersebut dianalisa. Kedua, Metode Perancangan: pada proses perancangan ini, datawarehouse dirancang dengan membuat dimensional modeling. Hal-hal tersebut yang akan diperhatikan ketika membuat dimensional modeling. Dimensional modeling sendiri terdiri dari: Identifikasi proses, identifikasi fact, identifikasi dimensi, implementasi datawarehouse, dan pembersihan data source. 


\section{HASIL DAN PEMBAHASAN}

\section{Metode Kimball}

Metode Kimball adalah metode pengembangan Datawarehouse yang dikembangkan oleh Ralph Kimball pada tahun 1980-an. Metode ini juga diketahui oleh sebagian orang sebagai dimensional modelling. Metode ini sudah menjadi standar pengembangan data warehouse selain metode inmon. Proses pengembangan data warehouse dengan metode ini adalah bottom-up, yaitu dengan membangun datamart pada department-department yang sudah memiliki inisiatif dan membutuhkan. Kemudian proses integrasi data mart dilakukan sehingga informasi yang tersimpan di data warehouse berbentuk multi dimensional dan sudah dilakukan denormalisasi. Breslin (2004) mengatakan, "Metode Kimball berbeda dalam beberapa hal dengan pengembangan database tradisional. Salah satu yang sangat berbeda alaha datawarehouse yang dibangun dengan Metode Kimball mengunakan teknik data modellin, yang disebut : Dimensional Data Modelling."

\section{Datawarehouse Life Cycle}

Datawarehouse life cycle adalah proses membangun datawarehouse dengan metode Kimball. Datawarehouse life cycle berbeda dengan konsep System Development Life Cycle (SDLC). Konsep ini terdiri dari beberapa proses yang sifatnya pararel/urutan sampai pada phase maintenance. Kimball mengatakan:

"Keberhasilan pelaksanaan datawarehouse tergantung pada integrasi yang tepat dari berbagai tugas dan komponen. Tidak cukup hanya memiliki data model yang terbaik atau teknologi yang terbaik saja - banyak aspek dari sebuat project datawarehouse perlu disatukan, seperti konduktor yang sedang menyatukan berbagai instrumen dalam sebuah konser. Satu instrumen tidak bisa mempresentasikan satu konser yang utuh. Datawarehouse harus menyatukan seтиa aspek dalam projek pengembangan sehingga dapat berhasil. Datewarehouse life cycle seperti form penilaian dari konduktor untuk memastikan bahwa satu tahapan dalam projek berada dalam urutan yang benar dan dalam waktu yang tepat." (Kimbal, et. al., 2008)

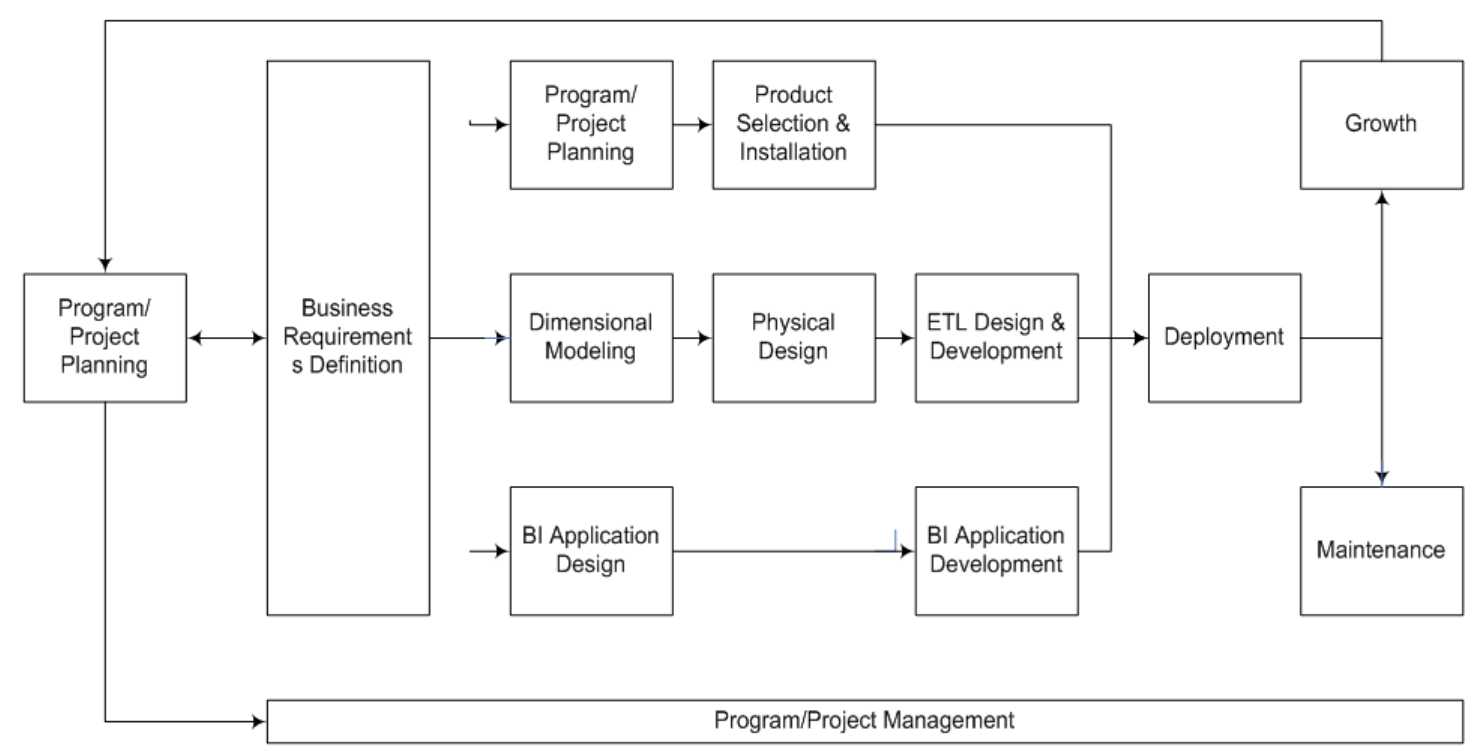

Gambar 1 Datawarehouse Life Cycle Flow 
Datawarehouse Life Cycle terdiri dari proses-proses yang saling terkait satu sama lain. Pertama, program/project planning: Ini adalah aktivitas pertama dalam proses pengembangan datawarehouse. Fase ini dilakukan baik dari managemen dan juga tim teknikal. output dari fase ini adalah project planning, semakin baik fase ini dipersiapkan semakin baik hasil dari keseluruhan projek. Yang dilakukan dalam fase ini adalah (1) Melakukan definisi dan ruang lingkup projek. (2) Melakukan perencanaan projek. (3) Melakukan pengelolaan projek, baik sumber daya manusia, budget dan alat-alat.

Kedua, Program/project management adalah pendekatan untuk melakukan perencanaan, pengorganisasian, motivasi dan kontrol sumber daya untuk mencapai tujuan tertentu. Project management yang dilakukan untuk projek datawarehouse, mengunakan referensi yang sama seperti proyek lainnya, yaitu: Project Management Body of Knowledge (PMBOK). Ketiga, business requirement definition: yang dilakukan dalam fase ini adalah melakukan interview kebutuhan analisa dari top management. Untuk melakukan business requirement dari top management berikut langkahlangkah yang harus diikuti sesuai dengan gambar yang tertera dibawah ini. Langkah-langkah ini digunakan untuk membuat draft pertanyaan dan juga mengetahui proses bisnis dari industri yang bersangkutan. Hal ini dilakukan agar proses diskusi berjalan lebih lancar dan cepat.

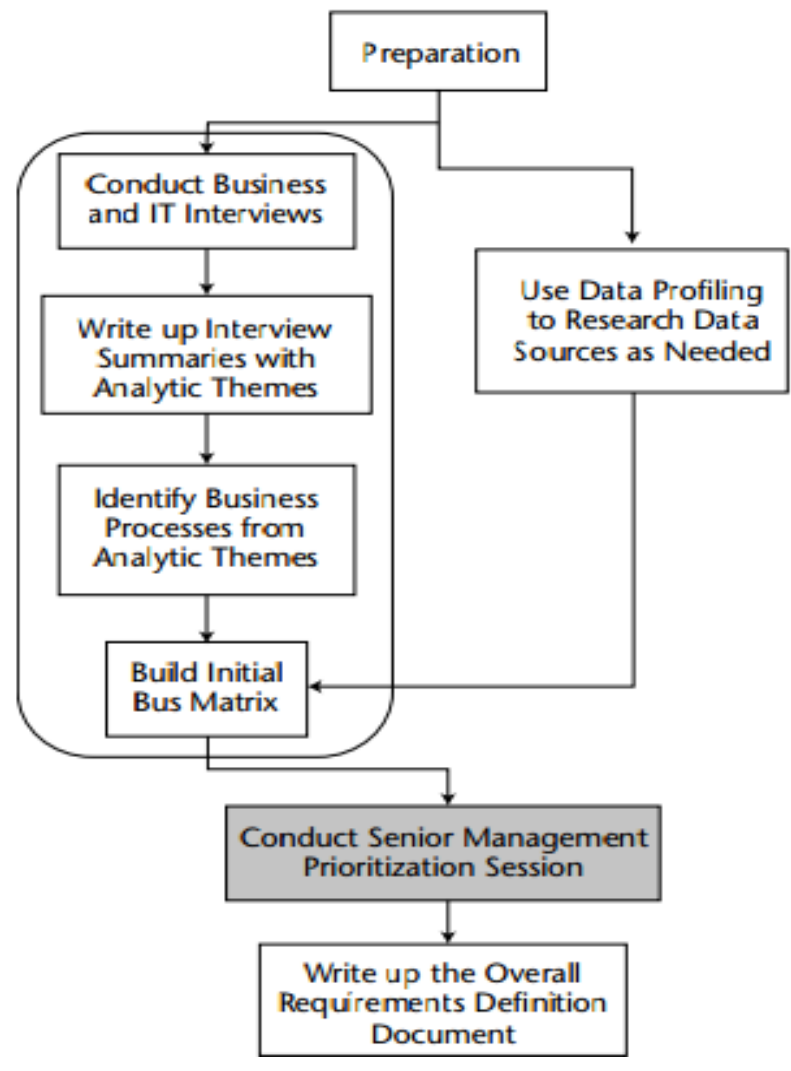

Gambar 2 The Enterprise Requirements of Definition Process Flow Chart

Keempat, technology track. Di fase teknologi ini akan dilakukan dua aktivitas, yaitu: (1) Technical architecture design, yaitu membuat kerangka teknikal pengembangan datawarehouse. (2) Product Selection \& Installation, yaitu tahap untuk menentukan produk/software yang dipakai untuk pengembangan datawarehouse yang paling cocok dengan technical architecture design yang sudah dilakukan di tahap sebelumnya. Kelima, data track. Di fase data ini akan dilakukan tiga aktivitas, yaitu: (1) Dimensional modelling, yaitu proses pembentukan dimensi dan fact serta star schema. 
Pembentukan star schema ini sesuai dengan metode Kimball. (2) Physical design, yaitu proses pembentukan metadata di database, dengan merincikan semua atribut dari tiap-tiap dimensi dan fact yang sudah didesain pada tahap sebelumnya. (3) ETL Design \& Development, yaitu proses melakukan extract, transform dan load dari source ke target environment. Proses tersebut menurut Kimball dibagi menjadi empat proses besar yaitu: (1) Ektrak data, (2) Pembersihan data, (3) Penyajian data, (4) Mengatur distem ETL.

Keenam, business intelligence application track. Di fase ini dilakukan dua aktivitas, yaitu : (1) BI application design, yaitu melakukan desain bentuk dashboard, report dan analisa untuk memenuhi kebutuhan bisnis. (2) BI application development, yaitu mengembangkan aplikasi BI dari desain yang sudah di lakukan di tahap sebelumnya. Ketujuh, deployment. Fase ini adalah fase terakhir dari proses development, yang dilakukan pada fase ini adalah: (1) Testing keseluruhan proses mulai dari technology track, data track dan business intelligent track. (2) Membuat semua dokumentasi berhubungan dengan tiap-tiap tahap pengembangan datawarehouse. (3) Melakukan pelatihan terhadap admin, dan juga bisnis user.

Kedelapan, Fase maintenance memastikan agar sistem yang sudah GO LIVE selalu dalam keadaan aktif dan dapat selalu dipakai oleh user. Langkah-langkah yang dilakukan dalam fase ini biasanya meliputi : rekonsiliasi data, monitoring dan performance tuning. Kesembelian, fase Growth terjadi ketika data bertambah banyak, atau kebutuhan analisa meningkat. Hal tersebut mengakibatkan proyek pengembangan datawarehouse harus diulangi lagi dari awal, baik itu pengembangan skala besar ataupun penambahan beberapa star schema baru.

\section{Proses Bisnis \& Proses ERP Manufaktur Fahrenheit}

Fahrenheit adalah perusahaan farmasi yang berdiri pada tahun 1988, atas prakarsa beberapa dokter. Dengan credo quality of better health, Fahrenheit terus berkembang hingga masuk peringkat 10 besar perusahaan farmasi di Indonesia. Proses manufaktur di Fahrenheit terdiri dari alat-alat modern dan telah memenuhi standar internasional yaitu Good Manufacturing Practice (GMP). Saat ini untuk setiap produk yang dihasilkan sudah dilakukan quality assurance, yang terdiri dari Evaluasi preproduksi, Perencanaan quality, Standarisasi, Kalibrasi dan Perawatan, Dokumentasi Produk, dan Kontrol kedatangan material.

Untuk mendukung pengembangan manufaktur maka Fahrenheit melakukan implementasi ERP dengan keterkaitan antar modul seperti terlihat di gambar dibawah ini.

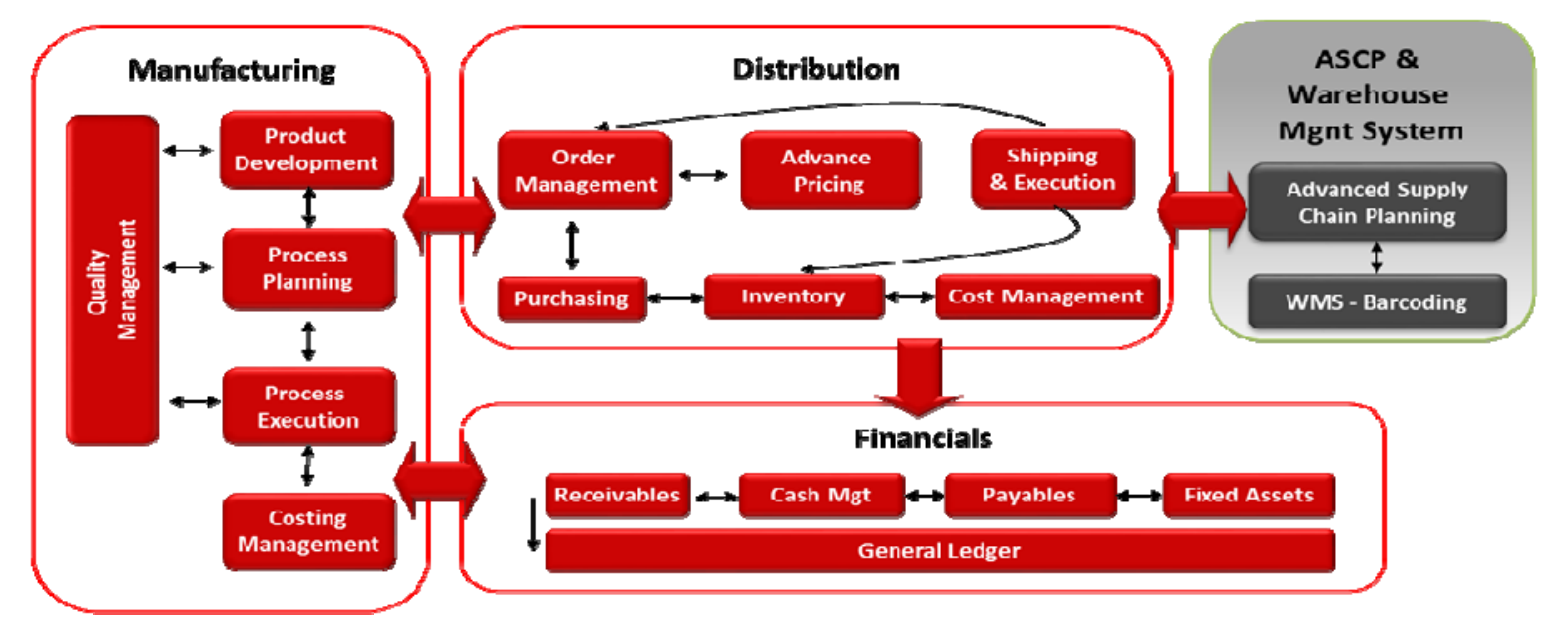

Gambar 3 Proses Bisnis ERP Manufaktur Fahrenheit 
Proses manufaktur dimulai dari proses produk development, bagian research \& development akan melakukan penelitian untuk membuat produk-produk baru dan setelah produk baru release maka dilanjutkan ke bagian PPIC (Production Planning and Inventory Control) untuk membeli bahan baku dan bahan kemas yang dibutuhkan untuk melakukan produksi. Proses berlanjut dengan melakukan produksi atas produk tersebut, dengan mencampur beberapa bahan baku untuk membentuk WIP, yang akan dipakai untuk proses produksi tahap berikutnya. Pada tahap akhir akan dilakukan pencampuran dengan bahan kemas, langkah ini sebut tahap pengemasan. Semua proses yang dijelaskan diatas dikontrol oleh bagian quality control, yang memeriksa kualitas bahan baku, bahan kemas dan proses dari tiap-tiap tahap produksi. Pada tahap ini beberapa hal yang dilakukan adalah kalibrasi alat, uji stabilitas, uji sterilisasi, dan lainnya. Kim (2012) mengatakan, "Metodology yang efektif untuk mengukur dan menganalisa kolaborasi kinerja dari manufatur harus di kembangkan. Hal ini akan membuat fungsi kolaborasi dapat mengatur dan meningkatkan relasi antara semua partisipant sehingga meningkatkan kinerja dari tiap-tiap individu untuk menghasilkan keunggulan bersaing seperti: efisiensi, qualitas, inovasi dan peningkatan terhadap respon dari customer.

\section{Dimensional Modelling Sistem Manufaktur Fahrenheit}

Kimball dan Margy (2002) mengatakan, "Istilah dimensi dan facts berasal dari penelitian gabungan yang diadakan oleh General Milis dan Darmouth University pada tahun 1960an. Di tahun 1970an, baik AC Nielsen dan IRI mengunakan istilah ini sebagai dimensional data mart."

\section{Analisa Inventory}

Untuk melakukan analisa inventory/stok, dibentuk dimensional modelling yang terdiri dari lima dimensi (Gambar 4) yaitu: (1) Dim - Time, berisi data waktu per hari yang disimpan dari tahun 2000 sampai 2050. (2) Dim - Plant, berisi data lokasi pabrik/gudang. (3) Dim - Product, berisi data bahan baku, bahan kemas. (4) Dim - FG Product, berisi data barang jadi. (5) Dim - Lot, berisi data kumpulan lot dari bahan baku, bahan kemas, dan barang jadi.

Dimensional modelling tersebut terdiri dari satu fact, yaitu Fact - Inventory Balance yang berisi data stock onhand untuk bahan baku, bahan kemas, dan barang jadi per hari. Data terkecil disimpan dalam bentuk lot number. Dari star schema di bawah, perusahaan bisa melakukan analisa on-hand, intransit dan wip dari berbagai kombinasi dimensi, sehingga dapat terlihat apakah inventory balance menunjukan saldo yang benar dan sesuai dengan total produksinya.

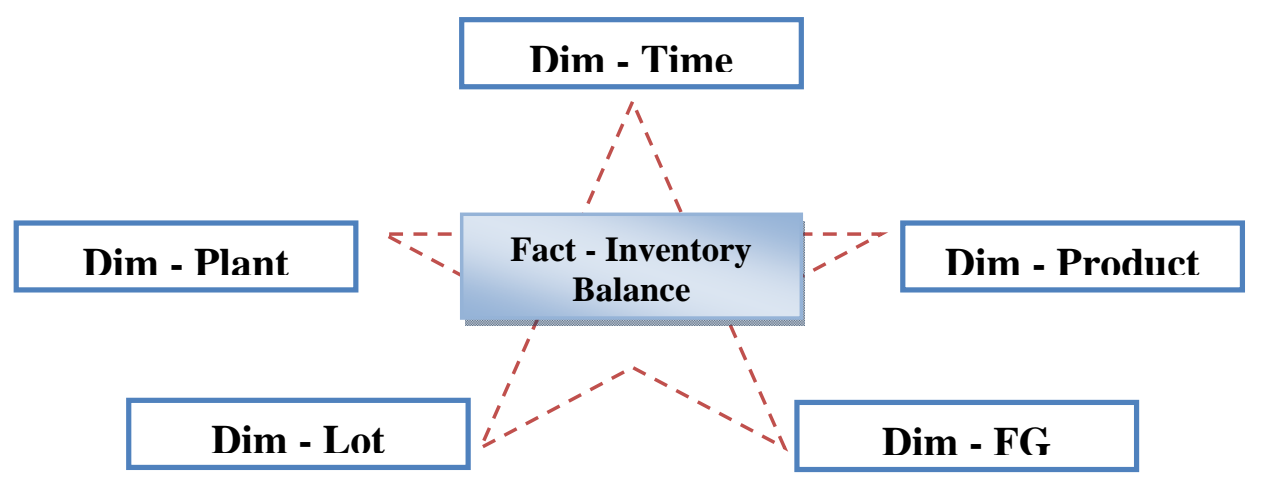

Gambar 4 Star Schema Inventory 


\section{Analisa Biaya Produksi}

Untuk melakukan analisa inventory/stok, dimensional modelling dibentuk seperti yang terdiri dari 5 dimensi (Gambar 5) yaitu: (1) Dim - Time, berisi data waktu per hari yang disimpan dari tahun 2000 sampai 2050. (2) Dim - Plant, berisi data lokasi pabrik/gudang. (3) Dim - Product, berisi data bahan baku, bahan kemas. (4) Dim - Lot, berisi data kumpulan lot dari bahan baku, bahan kemas, dan barang jadi. (5) Dim - Work Order, berisi data perintah kerja produksi.

Dimensional modelling tersebut terdiri dari satu fact, yaitu Fact - Production Cost yang berisi data cost produksi. Data terkecil disimpan dalam bentuk lot number. Dari star schema di bawah, perusahaan bisa melakukan analisa biaya produksi, biaya overhead, biaya resource, revenue, cogs, dan margin.

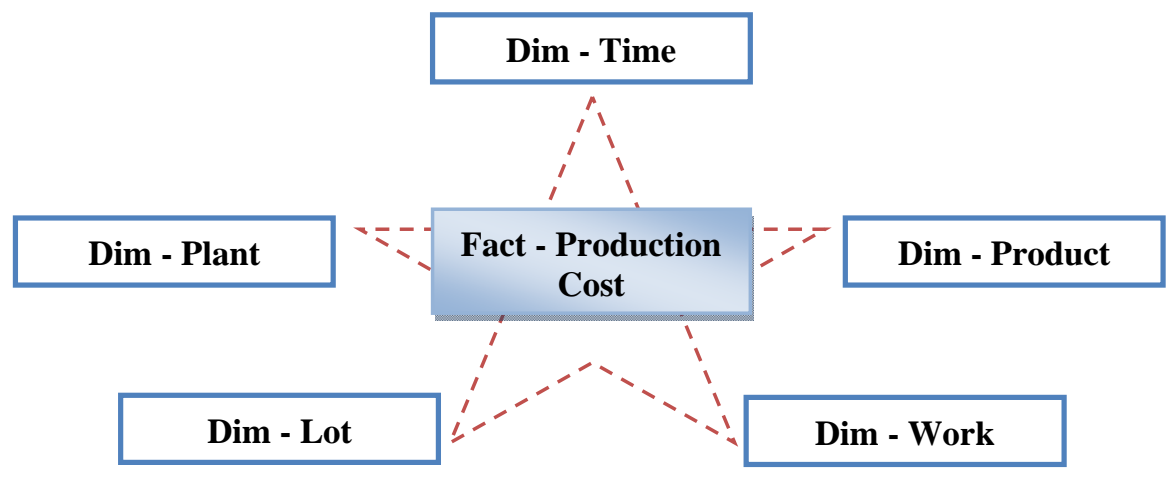

Gambar 5 Star Schema Production Cost

\section{Analisa Yield (Hasil) Produksi}

Untuk melakukan analisa inventory/stok, dibentuk dimensional modelling yang terdiri dari lima dimensi (Gambar 6) yaitu: (1) Dim - Time, berisi data waktu per hari yang disimpan dari tahun 2000 sampai 2050. (2) Dim - Plant, berisi data lokasi pabrik/gudang. (3) Dim - Product, berisi data bahan baku, bahan kemas. (4) Dim - Lot, berisi data kumpulan lot dari bahan baku, bahan kemas, dan barang jadi. (5) Dim - Work Order, berisi data perintah kerja produksi.

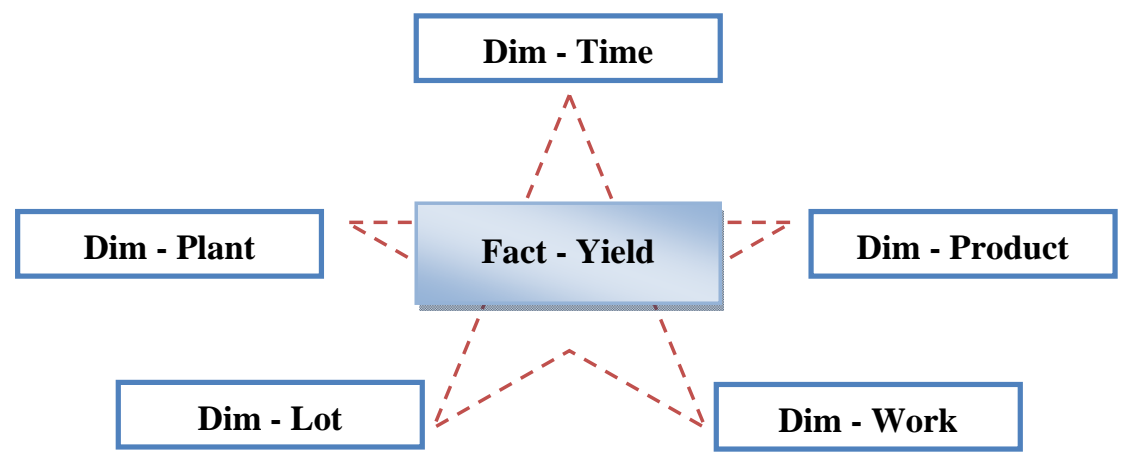

Gambar 6 Star Schema Yield 
Dimensional modelling tersebut terdiri dari 1 fact, yaitu Fact - Yield yang berisi data hasil produksi. Data terkecil disimpan dalam bentuk lot number. Dari star schema di atas, perusahaan bisa melakukan analisa pada yield per work order, sehingga bisa terlihat perbedaan antara actual dan plan. Hal ini dapat digunakan untuk mengkontrol terjadinya penyelewengan pada proses produksi.

\section{Analisa Resource Produksi}

Untuk melakukan analisa inventory/stok, dibentuk dimensional modelling yang terdiri dari 8 dimensi (Gambar 6) yaitu: Dim - Time, berisi data waktu per hari yang disimpan dari tahun 2000 sampai 2050. (2) Dim - Plant, berisi data lokasi pabrik/gudang. (3) Dim - Product, berisi data bahan baku, bahan kemas. (4) Dim - Lot, berisi data kumpulan lot dari bahan baku, bahan kemas, dan barang jadi. (5) Dim - Work Order, berisi data perintah kerja produksi. (6) Dim - Department, berisi data department yang ada diruang lingkup pabrik. (7) Dim - Resource, berisi data alat dan sdm yang dipakai untuk proses produksi. (8) Dim - Operation, berisi data waktu operasi produksi.

Dimensional modelling tersebut terdiri dari 1 fact, yaitu Fact - Resources yang berisi data hasil produksi. Data terkecil disimpan dalam bentuk lot number. Dari star schema di atas, perusahaan bisa melakukan analisa resource, sehingga bisa terlihat perbedaan antara actual dan plan dari resource tersebut. Hal ini dapat digunakan untuk mengkontrol workload di lingkungan produksi pabrik.

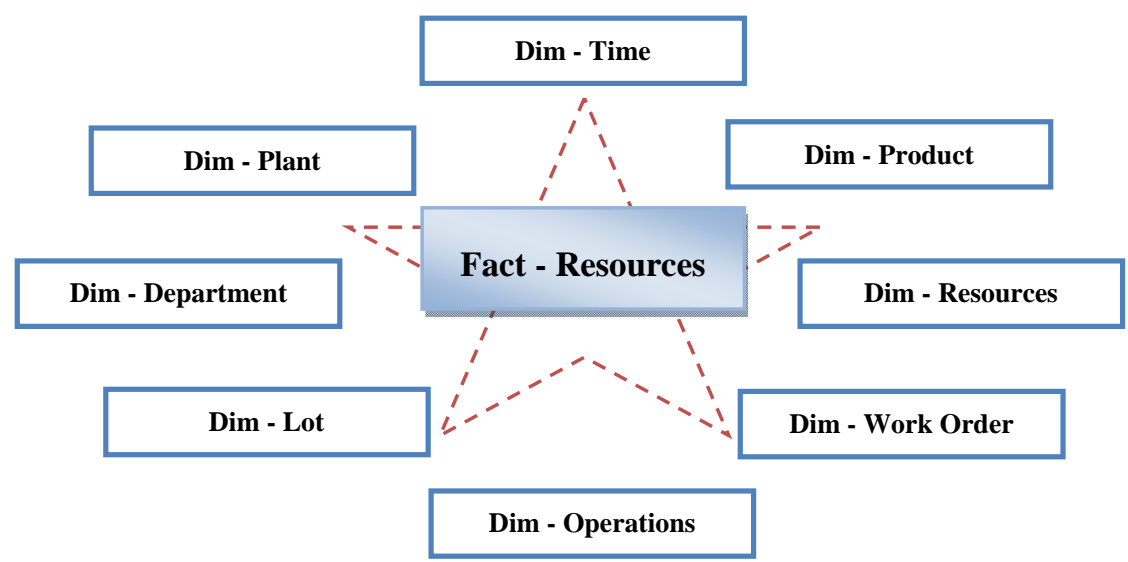

Gambar 7 Star Schema Resources

\section{SIMPULAN}

Metode Kimball untuk pengembangan datawarehouse bersifat bottom-up dan cocok digunakan untuk pengembangan datawarehouse per proses bisnis, dan bukan untuk keseluruhan bisnis perusahaan. Dalam kasus Fahreheit dimana mereka baru melakukan implementasi ERP, maka pendekatan metode Kimball untuk membangun datawarehouse manufatur mereka cocok untuk mengunakan metode ini. Kualitas data untuk tiap-tiap proses di ERP masih diragukan validitasnya, dan fokus utama dari bisnis adalah pada area manufatur.

Metode Kimball memberikan datamart yang jelas untuk tiap-tiap proses analisa di area manufatur. Star schema Inventory, Production Cost, Yield, dan juga Resource sudah dirancang. Dari star schema tersebut, maka perusahaan dapat melakukan analisa biaya produksi compare terhadap hasil, penyimpangan produksi, resource terbanyak, alokasi, serta monitoring stock bahan baku, bahan kemas maupun barang jadi. Selanjutnya, bisa dilihat mana yang slow moving, medium dan fast moving. Pengembangan datawarehouse pada manufatur ini dapat meningkatkan kolaborasi informasi 
yang akurat, up-to-date dan informatif untuk mendukung pengambilan keputusan strategis bisnis, memberikan inovasi dan kreatif dalam upaya meningkatkan cara kerja menjadi lebih efisiensi dan efektif, sehingga yang akhirnya memberikan keuntungan yang optimal bagi perusahaan.

\section{DAFTAR PUSTAKA}

Breslin, Mary. (2004). Datawarehousing Battle of The Giant: Comparing the Basic of the Kimball and Inmon Models . Business Intelligent Journal, 9 (1).

Kim, Aekyung., Kim, Kyuri. (2012). Business Process Warehouse For Manufacturing Collaboration. $41^{\text {th }}$ International Conference on Computers \& Industrial Engineering.

Kimball, R., Margy, R. (2002). The Data Warehouse Toolkit: The Complete Guide to Dimensional Modelling. Second edition. New York: John Wiley \& Sons.

Kimball, R., Ross, M., Thornthwaite, W., Mundy, J., \& Becker, B. (2008). The Data Warehouse Lifecycle Toolkit. Second edition. New York: John Wiley \& Sons.

Marketa, H., Hana. (2013). Business Intelligence and Implementation in a Small Enterprise. Journal of System Information, 4(2):1804-2724.

Saxena, S., Mathur, S. (2014). A Lifecycle based Testing of Data Warehouse. International Journal of Advanced Research in Computer Science and Software Engineering, 4(12), 518-523. 